\title{
On the Causal Attribution of Academic Achievement in College Students
}

\author{
Chuanping Lei \\ School of Arts, Qufu Normal University \\ Qufu 273165, Shandong, China \\ E-mail: kongying1986@yeah.net
}

Part of the key research project supported by China's 10th Five-year Plan for National Education Science (Project No.FBB030759).

\begin{abstract}
Based on causal attribution theory, we investigated the characteristics of causal attribution of academic achievement, expectancy change and emotional response in college students via a questionnaire survey. It was found that: (1) College students had different attributions on success and failure. Differences among students' grades and that between success and failure were significant while differences between genders were not significant. (2) College students had higher expectation when they came across failure, and they were willing to work hard to make progress. (3) College students would feel gratified and proud after success. They would feel compunctious and depressed after failure. Their emotional responses were stronger when they succeed.
\end{abstract}

Keywords: College students, Achievement attribution, Expectancy changes, Emotional response

\section{Introduction}

The causal attribution theory hypothesizes that within the scope of academic achievements, the motivation for "seeking understanding" causes students to make attributions toward their success or failure in studying. Such attributions will result in changes in expectations and emotions, which affects the individuals' motivations for learning and then their academic achievements.

Based on the previous studies, Weiner (1979), theoretician of attribution theory, proposes a three-dimensional attribution model of behaviour. He contends that the attributions toward success or failure are of great importance to understand achievement behaviour. In addition, people display different characteristics when they make attributions toward success and failure.

Since Weiner put forward his model, much research has been done on the causal attributions toward success and failure within the scope of academic achievements within and outside China. Researchers have found that students have different inclinations for success and failure, and there exist differences in causal attributions in terms of grade and gender. Unfortunately those studies were mainly conducted among students in primary and middle schools. Research targeted at college students has been so far sporadic. A systematic research into causal attributions on the part of college students is needed. Thus, based on causal attribution theory, the present author intends to investigate causal attributions, expectancy change and emotional responses of Chinese college students.

\section{Methodology}

\subsection{Subjects}

Totally, 1,400 subjects ranging from freshmen to seniors were selected from two universities in Yantai, Shandong Province. After subjects with invalid and incomplete data were rejected, 1,314 subjects were left. The number of subjects in each grade goes like as follows: 349 freshmen, 336 sophomores, 336 juniors and 293 seniors. The students in the same grade are similar in their ages and academic proficiency on the whole. 


\subsection{Instrument}

A questionnaire survey was adopted in the present study. The causal attribution scale is consisted of two sub-scales: a success one and a failure one, each presenting the presumptive situations of successful and failure situations within the scope of academic achievements. The success and failure questionnaires are made up of three parts respectively: causal attribution, expectancy change, and emotional responses.

\subsubsection{Causal Attribution Part}

This part is designed according to the $2 \times 2 \times 2$ causal dimensions, including 8 sun-scales: ISC (internal, stable, controllable, e.g. persistent diligence), ISU (internal, stable, uncontrollable, e.g. learning abilities), IUC (internal, unstable, controllable, e.g. temporary diligence, hasty cramming), IUU (internal, unstable, uncontrollable, e.g. mood, improvisation), ESC (external, stable, controllable, e.g. teaching quality, teacher's prejudice), ESU (external, stable, uncontrollable, e.g. the difficulty of the test paper), EUC (external, unstable, controllable, e.g. help from others), EUU (external, unstable, uncontrollable, e.g. luck). There are four questions in each scale. The total number of questions is thirty-six, including four questions for testing whether the subjects told a lie. Each question is followed by a five-point rating scale, ranging from absolutely incongruous ( 1 point) to absolutely congruous ( 5 points). The higher the point is, the more effect this factor has on success or failure.

\subsubsection{Expectancy change Part}

Two questions were designed in this part, which are "Do you think you can pass the next examination?" and "Would you like to work hard to make progress in your study?" The purpose was to investigate their expectation for future studying. The five-point rating scale was also used here.

\subsubsection{Emotional Response Part}

According to the characteristics of emotional responses, four aspects were recognized: gratification, pride, gratitude, excitement in the successful situations and guiltiness, self-abasement, resentment, bemoaning in the failure situations.

The calculating result of the homogeneity of the questionnaire was 0.813 , which showed this questionnaire proper was a reliable instrument with a high internal validity.

\subsection{Procedures}

The test was conducted during the evening self-study time. Questionnaires for success and failure were delivered every other week. The test order in the two universities was converse so as to eliminate the effect of the questionnaire order. The software SPSS 10.0 for Windows was used to analyze the collected data.

\section{Data Analysis and Results}

\subsection{General characteristics of causal attribution displayed by college students}

Table 1 shows the values of mean and standard deviation of the eight aspects in the successful and failure situations.

\section{Insert Table 1 Here}

From Table 1 it can be seen that: in the success situations, college students are aware of factors like teaching quality and persistent diligence, etc, while factors like luck and help from others are not considered as the main causes for success in examinations; in the failure situations, college students are aware of factors like poor improvisation, the difficult degree of test papers, and bad luck, while factors like poor teaching quality, lack of hard work are nor regarded as the main causes for poor performance in examinations. It can be concluded that in the success situations, college students mainly attribute the examination results to external factors, less to the internal factors; conversely, in the failure situations, they tend to attribute the results to internal factors, less to the external factors. Besides, ability is not the main factor affecting the academic achievements of college students, which is much different from that of students in primary and middle schools.

\subsection{Variance analysis of causal attributions toward academic achievements in college students}

We made the $2 \times 4 \times 2$ multiple covariances analysis of gender (male, female), grades $\left(1^{\text {st }}\right.$ year, $2^{\text {nd }}$ year, $3^{\text {rd }}$ year and $4^{\text {th }}$ year), and performance (success, failure), in hopes of finding out the differences in causal attributions among college students in different grades and of different genders (see Table 2).

\section{Insert Table 2 Here}

From Table 2, it can be seen that upon the variance determining the causes, the factor of performance (success and failure) is significant. The factor of grade displays differences in ISU, IUC, EUC, ESU, and EUU, which shows that the factor of grade has an effect on causal attributions by college students. As regards "age", this factor plays an unimportant role in the causal attributions by college students. And the last point is the same with that found in students in primary and middle schools. 
On the aspect of mutual effect, the co-effect of gender and performance (success and failure) has great influence on the awareness of ISC, IUC, IUU, ESC, ESU by college students. The co-effect of performance (success and failure) has great influence on the awareness of ISC, ISU, IUU, ESC, EUC, EUU, but the factor of performance (success and failure) dominates. The co-effect of gender and age has little influence on the eight aspects.

\subsection{Causal attribution and expectancy for success in college students}

There exists an internal relationship between the stable causal attributions of reasons and expectations for success. Weiner (1979) points out the stable causal attributions of reasons will affect the continuation of expectations for success. If the students attribute their academic achievements to stable reasons, they will have less expectation for changing the present results. If the students attribute their academic achievements to unstable reasons, they will have more expectation for changing the present results. Table 3 and 4 show the test results of means, standard deviations and variance analysis of success and failure for the change of expectations.

\section{Insert Table 3 Here \\ Insert Table 4 Here}

From Table 4, it can be seen that upon the aspect of being successful or not, gender makes little difference while grade and performance show much difference. From $1^{\text {st }}$ to $4^{\text {th }}$ year, college students have more and more confidence, and they think they can succeed in the future. On the mutual effect aspect, the value $\mathrm{F}$ is so significance.

Upon the aspect of being willing or not, gender, grade and performance all reach the significance level. Whether to be successful or not, male college students are more willing than females to work hard so as to make progress in studying. In addition, students in higher grade, female or male, are willing to work hard on their study. And they have more expectation when they fail. However, on the aspect of mutual effect, the significance level does not come up.

\subsection{Characteristics of emotional responses of college students}

Within the framework of causal attribution theory, cause on each dimension can be connected with a group of particular emotional responses. Considering the ways and characteristics of emotional expressions of Chinese college students, we selected a group of emotions corresponding with the tendency in causal attributions in the present study. We selected pride, gratification, gratitude, excitement in the successful situations and self-abasement, guiltiness, resentment, bemoaning in the failure situations.

It is found that within the range of academic achievements, college students mainly have emotions of gratification and pride when they succeed, and guiltiness and bemoaning when they fail. The variance analysis shows that there exist main effects on emotional responses of gratification-guiltiness and gratitude-resentment. Except for excitement-bemoaning, there exist significant differences in the other three groups of emotional responses. On the aspect of mutual effect, the co-effect of grade and performance (success or failure) has main effect on the emotional responses of pride- self-abasement and gratification-guiltiness (see Table 5).

\section{Insert Table 5 Here}

Besides, the T-test of gender differences shows that upon the successful results, male students have more gratitude $(t=2.817, p<0.005)$ and more pride $(t=2.781, p<0.005)$ than females; upon the failure results, female students significantly have more self-abasement $(t=2.795, p<0.01)$, more guiltiness $(t=4.927, p<0.001)$, and more bemoaning $(t=4.724, p<0.001)$. Other differences concerning gender are not so significant.

\section{Discussions}

\subsection{Tendencies in causal attribution toward academic achievements of college students}

The present study finds out that there are differences in the characteristics of causal attributions toward success and failure on the part of college students. Specifically speaking, such differences lie in the different orders of the eight main reasons affecting success and failure as well as the significant effects of the successful or failure results. There are similarities and differences in the characteristics of causal attributions displayed by college students and that of students in primary and middle schools.

First of all, because of differences in knowledge, maturity, and growth, there are significant differences in causal attributions toward academic achievements in college students and students in primary and middle schools. The present author argues that such differences are in agreement with their cognitive maturity. College students in higher grades, after succeeding or failing many times, have developed a relatively stable self-concept. They have stable understanding of the reasons for their success or failure in their studying.

Secondly, it is the Chinese traditional culture that affects the causal attributions of the students. The spirit of humility makes the students modest when they succeed. So they tend to attribute their success to external factors, esp. the improvement of teaching quality. Such a "humble" character penetrates the whole process of causal attributions, which is unique of Chinese students. In our previous studies, we have verified this point. But further investigation still needs to 
be made.

Last but not least, college students have the encouragement to shoulder their responsibility when confronted with failure. Facing with failure, college students consider that their internal factors cause the poor results, which is the specific representation of having responsibility for studying. In other words, there does not exist the self-interest variance of causal attributions in college students. And they are very different from students in primary and middle schools in this case.

\subsection{Expectations for success of college students}

According to causal attribution theory, the factor of cognition is the main condition for the increase or decrease in expectations. If the student has great hope for his future study, he will be full of confidence and work hard. It is found in the present study that college students are apparently aware that the failure results can be changed and they are willing to make great efforts to achieve future success. This is the same with the expectancy change of students in primary and middle schools. The underlying factor is the traditional education in China.

\subsection{Characteristics of emotional responses of college students}

In the successful situations, college students consider that constant diligence is of greater importance and they have emotions of gratification and pride. In the failure situations, they consider that improvisation is more important, and they feel guilty and depressed. In addition, college students would not like to accept the negative emotions after failure. So they show significant emotional responses after success. One possible reason is that during the four-year college time, failure in examinations is few so that they do not display strong negative emotions after failure. Of course, further research needs to be done in the future. Moreover, facing with success, male students have stronger positive emotional responses that female students, while female students have stronger negative emotional responses when confronted with failure. This phenomenon deserves special attention. Perhaps it is connected with the whole social atmosphere and traditional values.

\section{Conclusion}

Here are the major findings of the present study: (1) College students display different causal cognition toward success and failure. In the successful situations, they tend to attribute the results of examinations to external factors, while in failure situations, they tend to attribute the results to internal factors. (2) The characteristic of causal attributions toward success and failure by college students is significant in the parameter of "grade". Besides, on the variance determining various causes, the effect of success or failure is obvious. (3) The parameter of "gender" has little effect on causal attributions toward academic achievements. (4) As regards expectations, there exist significant levels in different grades and differences in the successful or failure results. The higher their grade, the more willing they are to work hard. Facing with failure, college students have more expectations. (5) When they succeed, college students mainly have emotions of gratification and pride, with less excitement; when they fail, they mainly have emotions of guiltiness and bemoaning, with less resentment. And they have stronger emotional responses after succeeding.

\section{References}

Han, Rensheng. (1996). On the Attribution of Success or Failure of Primary and Middle School Students in Examinations. Acta Psychologica Sinica, 28(2): 140-147.

Hargreaves D. J. and Colley A. W. (1987). The Psychology of Sex Role. Hemisphere Publishing Corp. 170-186.

Weiner B. (1979). A theory of motivation for some classroom experiences. Journal of Educational Psychology, 71(1): $3-25$.

Weiner B. (1986). An attributional theory of motivation and emotion. New York: Springer-Verlag, Inc. 67-71.

White P A. (1990). Causal powers, causal questions, and the place of regularity information in causal attribution. British Journal of Psychology, 83, 161-188. 
Table 1. The overall means and standard deviation values of the causal attributions toward success and failure in college students

\begin{tabular}{cccccccc}
\hline \multicolumn{7}{c}{ Causes } \\
\hline ISC & ISU & IUC & IUU & ESC & ESU & EUC & EUU \\
Results $M=S D$ & $M \pm S D$ & $M=S D$ & $M \pm S D$ & $M=S D$ & $M \pm S D$ & $M=S D$ & $M \pm S D$ \\
\hline Success $3.429 \pm 0.6833$ & $3.310 \pm 0.680$ & $3.421 \pm 0.634$ & $3.486 \pm 0.671$ & $3.538 \pm 0.681$ & $3.232 \pm 0.585$ & $3.139 \pm 0.603$ & $3.132 \pm 0.616$ \\
Failure 2.651 \pm 0.762 & $2.713=0.775$ & $2.612 \pm 0.716$ & $2.886 \pm 0.787$ & $2.592=0.736$ & $2.849 \pm 0.661$ & $2.767=0.667$ & $2.834 \pm 0.663$ \\
\hline
\end{tabular}

Table 2. Variance analysis of the eight aspects in gender, grade and performance (Value $F$ )

\begin{tabular}{|c|c|c|c|c|c|c|c|c|c|}
\hline \multirow[b]{2}{*}{ Casus } & \multicolumn{4}{|c|}{ Main Effect } & \multirow[b]{2}{*}{ Gonder: } & \multicolumn{4}{|c|}{ Mutual Effect } \\
\hline & Geader Gr & Grad. & Perfore & axace & & Pesformanese & Gesader X Grade & Porformance X Grad, & Geader X Purformases X Gradv \\
\hline ISC & 1. 277 & & 358 & 520. & $661 \% *$ & 5.9758 & 0.737 & 5.01488 & 1.985 \\
\hline ISU & 0.008 & & $508 \% 8 *$ & * 689 & $373 * 4$ & 0.915 & 1. 286 & 5. 444888 & 3. $8594 *$ \\
\hline IUC & 0.004 & & $028 \% 8$ & 698. & $373 * 4$ & 6.5158 & 0.109 & 2. 341 & 0.437 \\
\hline IUU & 1.800 & & 542 & 339. & $821 * 1 *$ & $5.576 \%$ & 0.505 & 2. 8838 & 0.653 \\
\hline ESC & 1.971 & & 440 & 840. & $052 * 4 *$ & 8. 34088 & 0.417 & 14. $74788 \%$ & 2.012 \\
\hline EUC & 2. 635 & & 9188 & 179. & $299 \% *$ & 2.091 & 0.595 & $7.378 \times 88$ & 2. $929 *$ \\
\hline ESU & 2. 532 & & 90688 & 211 & $984 * 4 *$ & 11. 25388 & 0.727 & 1. 163 & 4. 175 \\
\hline EUU & 0.928 & 10. & $.453 * *$ & $* * 119$ & $738 \% 4$ & 0.303 & 2. 535 & 7. 324888 & 1. 927 \\
\hline
\end{tabular}

* $p<0.05, \quad$ *⿻; $p<0.01, \quad$ wow $p<0.001$, (hereinafter the same)

Table 3. The means and standard deviation of the change of expectations on success and failure of college students

\begin{tabular}{ccccc}
\hline & \multicolumn{2}{c}{ Success } & \multicolumn{2}{c}{ Failure } \\
\cline { 2 - 5 } & Successful or not & willing or not & successful or not & wiling or not \\
Grade & $M=S D$ & $M \pm S D$ & $M=S D$ & $M=S D$ \\
\hline $1^{\text {th }}$ year & $2.174=0.884$ & $1.713 \pm 0.801$ & $2.300 \pm 0.990$ & $1.828 \pm 0.931$ \\
$2^{\text {ndt }}$ year & $2.241 \pm 0.945$ & $1.830 \pm 0.896$ & $2.297 \pm 0.989$ & $1.967 \pm 1.028$ \\
$3^{\text {th }}$ year & $2.238 \pm 0.902$ & $1.776 \pm 0.867$ & $2.354 \pm 1.085$ & $2.017 \pm 1.111$ \\
$4^{\text {th }}$ year & $2.286 \pm 1.016$ & $2.167 \pm 1.126$ & $2.580 \pm 1.130$ & $2.283 \pm 1.097$ \\
\hline
\end{tabular}


Table 4. The variance analysis of the change of expectations on success and failure of college students (Value $F$ )

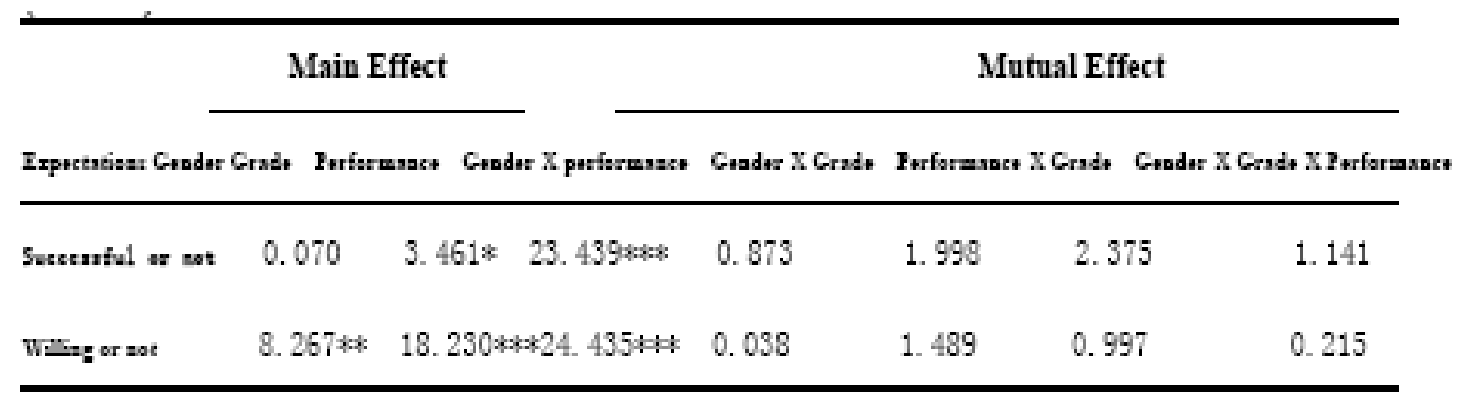

Table 5. The variance analysis of grade and performance results (success or failure) (Value F)

\begin{tabular}{|c|c|c|c|}
\hline \multirow[b]{2}{*}{ Emotions } & \multirow{2}{*}{$\begin{array}{l}\text { Main Effect } \\
\text { Grade }\end{array}$} & \multicolumn{2}{|c|}{ Mutual Effect } \\
\hline & & Performance & Performance Grade \\
\hline pride-self-abasement & 0.683 & $168.809^{\text {thth }}$ & $2.813^{*}$ \\
\hline gratification一guiltiness & $3.518^{\circ}$ & $129.735^{\text {*n* }}$ & $4.364^{* *}$ \\
\hline gratitude-resentment & $6.511^{* * 40}$ & $64.357^{000}$ & 0.403 \\
\hline excitement-bemoaning & 1.977 & 0.111 & 1.363 \\
\hline
\end{tabular}

\section{Appendix 1. The Causal Attribution Questionnaire of College Students' Performance in Examinations (A)}

Dear students,

We wish you could help us fill a questionnaire, which is about the reasons why you are SATISFIED with your scores. The answers are divided into 5 rankings, ranging from "absolutely congruous" to "absolutely incongruous". Please answer each question honestly and frankly with the mark " $\sqrt{ }$ " according to your own experience. There are no "correct" answers. All the data collected will be highly confidential and will be used for the research only. Thanks for participating in our study.

College Name

Department

You are from: city countryside

1 I feel calm when I take in examinations.

2 I have strong ability in analyzing and summarizing what the teacher teach in the class so that I grasp the main points.

3 The majority of my classmates do well in this subject.

4 The test paper is unexpectedly easy.

5 I never put off till tomorrow what can be done today.

6 Our teachers prepare and teach the lessons very well.
Grade___ Gender ___ Age

$\begin{array}{ccccc}\text { Absolutely } & \begin{array}{c}\text { Basically } \\ \text { Incongruous }\end{array} & \begin{array}{c}\text { Not } \\ \text { Incongruous }\end{array} & \begin{array}{c}\text { Busically } \\ \text { Congruous }\end{array} & \begin{array}{c}\text { Absolutely } \\ \text { Congruous }\end{array} \\ 1 & 2 & 3 & 4 & 5 \\ 1 & 2 & 3 & 4 & 5\end{array}$

$\begin{array}{lllll}1 & 2 & 3 & 4 & 5\end{array}$

$\begin{array}{lllll}1 & 2 & 3 & 4 & 5\end{array}$

$\begin{array}{lllll}1 & 2 & 3 & 4 & 5\end{array}$


7 I can finish the tasks of preview and revision given by the teacher.

8 I have a good memory so that I can remember what I have just learnt.

9 I take the revision lessons seriously and remember the key points before taking the examinations.

10 I feel energetic in examinations.

Absolutely

Incongruous
Basically

Incongruous
Not Basically

Sure Congruous Congruous
1

1

1
2

2

2
3

3

3
4

4

4
5

5

5

11 I have done some of the questions in the test paper during the revision period.

12 I am never absent-minded in class.

13 The contents of this subject are specific and connected with the reality.

14 The teacher will help us review what we have learnt before the examinations.

15 I will finish my homework consciously after class.

16 The lively teaching can appeal to us.

17 I won't go out with my classmates for relaxation during the revision period.

18 I did not come across catch questions.

19 This subject is easy to learn.

20 Someone will help me review what I have learnt before examinations.

21 I can concentrate on studying in my daily life.

22 I can guess what the teacher will test during the revision period.

23 I read carefully the requirements for each question and do revision when I am in examinations.

24 My classmates all study hard and we have a good learning atmosphere.

$\begin{array}{llllll}1 & 2 & 3 & 4 & 5\end{array}$

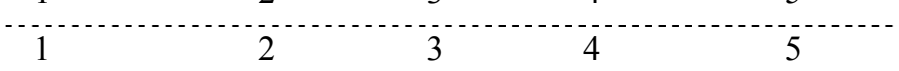

$\begin{array}{lllll}1 & 2 & 3 & 4 & 5 \\ 1 & 2 & 3 & 4 & 5\end{array}$

$\begin{array}{lllll}1 & 2 & 3 & 4 & 5\end{array}$

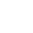




\section{Absolutely Basically Not Basically Absolutely \\ Incongruous Incongruous Sure Congruous Congruous}

the revision period.

32 I have a plan for my studying so that I can make reasonable arrangement of my time.

33 I feel ease when I do the questions in the test papers.

34 The teacher takes no prejudice to anyone when grading our test papers.

35 I have good foundation in studying so that I can grasp the basic knowledge in the textbooks.

36 I stay up late into night during the examination period.

37 I think I can do well in the coming examinations.

38 I am willing to work hard so as to make progress in studying.

$\begin{array}{lllll}1 & 2 & 3 & 4 & 5 \\ 1 & 2 & 3 & 4 & 5 \\ 1 & 2 & 3 & 4 & 5 \\ 1 & 2 & 3 & 4 & 5\end{array}$

5 5 5 5

9 When I hear the examination results this time, I feel:
(1) pride
(2) gratified
(3) grateful
(4) excited

1

1

2

2

2

3

3

4

5

1

3

4

5 


\section{Appendix 2. The Causal Attribution Questionnaire of College Students' Performance in Examinations (B)}

Dear students,

We wish you could help us fill a questionnaire, which is about the reasons why you are UNSATISFIED with your scores. The answers are divided into 5 rankings, ranging from "absolutely congruous" to "absolutely incongruous". Please answer each question honestly and frankly with the mark " $\sqrt{ }$ " according to your own experience. There are no "correct" answers. All the data collected will be highly confidential and will be used for the research only. Thanks for participating in our study.

\section{College Name}

Department

Grade

Gender

Age

You are from: city countryside

\begin{tabular}{|c|c|c|c|c|c|c|}
\hline & & $\begin{array}{l}\text { Absolutely } \\
\text { Incongruous }\end{array}$ & $\begin{array}{l}\text { Basically } \\
\text { Incongruous }\end{array}$ & $\begin{array}{l}\text { Not } \\
\text { Sure }\end{array}$ & $\begin{array}{l}\text { Basically } \\
\text { Congruous }\end{array}$ & $\begin{array}{l}\text { Absolutely } \\
\text { Congruous }\end{array}$ \\
\hline 1 & I do not feel calm when I take in examinations. & 1 & 2 & 3 & 4 & 5 \\
\hline 2 & $\begin{array}{l}\text { I have poor ability in analyzing and } \\
\text { summarizing what the teacher teach in the class } \\
\text { so that I can not grasp the main points. }\end{array}$ & 1 & 2 & 3 & 4 & 5 \\
\hline 3 & $\begin{array}{l}\text { The majority of my classmates do not do well } \\
\text { in this subject. }\end{array}$ & 1 & 2 & 3 & 4 & 5 \\
\hline 4 & The test paper is unexpectedly difficult. & 1 & 2 & 3 & 4 & 5 \\
\hline 5 & $\begin{array}{l}\text { I always put off till tomorrow what can be done } \\
\text { today. }\end{array}$ & 1 & 2 & 3 & 4 & 5 \\
\hline 6 & $\begin{array}{l}\text { Our teachers do not prepare and teach the } \\
\text { lessons well. }\end{array}$ & 1 & 2 & 3 & 4 & 5 \\
\hline 7 & $\begin{array}{l}\text { I cannot finish the tasks of preview and } \\
\text { revision given by the teacher. }\end{array}$ & 1 & 2 & 3 & 4 & 5 \\
\hline 8 & $\begin{array}{l}\text { I have a poor memory so that I cannot } \\
\text { remember what I have just learnt. }\end{array}$ & 1 & 2 & 3 & 4 & 5 \\
\hline 9 & $\begin{array}{l}\text { I do not take the revision lessons seriously and } \\
\text { cannot remember the key points before taking } \\
\text { the examinations. }\end{array}$ & 1 & 2 & 3 & 4 & 5 \\
\hline 10 & I feel tired in examinations. & 1 & 2 & 3 & 4 & 5 \\
\hline 11 & $\begin{array}{l}\text { I have never done some of the questions in the } \\
\text { test paper during the revision period. }\end{array}$ & 1 & 2 & 3 & 4 & 5 \\
\hline 12 & I am always absent-minded in class. & 1 & 2 & 3 & 4 & 5 \\
\hline 13 & $\begin{array}{l}\text { The contents of this subject are abstract and not } \\
\text { connected with the reality. }\end{array}$ & 1 & 2 & 3 & 4 & 5 \\
\hline 14 & $\begin{array}{l}\text { The teacher will not help us review what we } \\
\text { have learnt before the examinations. }\end{array}$ & 1 & 2 & 3 & 4 & 5 \\
\hline 15 & $\begin{array}{l}\text { I cannot finish my homework consciously after } \\
\text { class. }\end{array}$ & 1 & 2 & 3 & 4 & 5 \\
\hline 16 & What the teacher teaches does not appeal to us. & 1 & 2 & 3 & 4 & 5 \\
\hline 17 & $\begin{array}{l}\text { I often go out with my classmates for relaxation } \\
\text { during the revision period. }\end{array}$ & 1 & 2 & 3 & 4 & 5 \\
\hline 18 & I came across catch questions in examinations. & 1 & 2 & 3 & 4 & 5 \\
\hline 19 & This subject is difficult to learn. & 1 & 2 & 3 & 4 & 5 \\
\hline 20 & $\begin{array}{l}\text { No one will help me review what I have learnt } \\
\text { before examinations. }\end{array}$ & 1 & 2 & 3 & 4 & 5 \\
\hline
\end{tabular}




\section{Absolutely Basically Not Basically Absolutely \\ Incongruous Incongruous Sure Congruous Congruous}

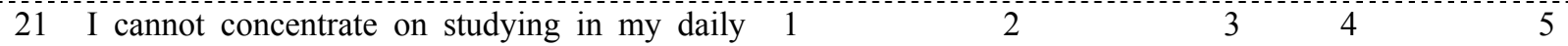
life.

22 I cannot guess what the teacher will test during 1 the revision period.

23 I read carelessly the requirements for each 1 question and do not do revision after I finish the test papers.

24 My classmates do not study hard and we have a 1 bad learning atmosphere.

25 I will keep on watching films during the 1 examination period.

$\begin{array}{llll}2 & 3 & 4 & 5 \\ 2 & 3 & 4 & 5 \\ 2 & 3 & 4 & 5 \\ 2 & 3 & 4 & 5\end{array}$

26 I have some burdens when taking the 1 examinations.

27 I cannot understand thoroughly what the teacher 1 teaches us.

28 Our teachers cannot specify the difficult points 1 and key points.

29 I will turn to others for help when I come across 1 difficult questions immediately.

30 I have no interest in learning.

31 Good friends do not help each other during the 1 revision period.

32 I have no plan for my studying so that I cannot 1 make reasonable arrangement of my time.

33 I feel nervous when I do the questions in the 1 test papers.

34 The teacher takes some prejudice when grading 1 our test papers.

35 I have poor foundation in studying so that I 1 cannot grasp the basic knowledge in the textbooks.

36 I do not stay up late into night during the 1 examination period.

37 I think I can do well in the coming 1 examinations.

38 I am willing to work hard so as to make 1 progress in studying.

2

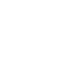

2

2

2

2

2
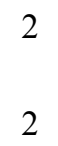

2

2

2

3

4

39 When I hear the examination results this time, I feel:
(1) self-abased
(2) guilty
(3) angry
(4) depressed 